Article

\title{
Zeolite Supported Ionic Liquid Catalysts for the Hydrochlorination of Acetylene
}

\author{
Bolin Wang, Huixia Lai, Yuxue Yue, Gangfeng Sheng, Yaqin Deng, Haihua He, Lingling Guo, \\ Jia Zhao * and Xiaonian $\mathrm{Li}^{*}$ \\ Industrial Catalysis Institute, Laboratory Breeding Base of Green Chemistry-Synthesis Technology, \\ Zhejiang University of Technology, Hangzhou 310014, China; wbl501028@outlook.com (B.W.); \\ laihuixia00@outlook.com (H.L.); yueyuxue@outlook.com (Y.Y.); shenggangfeng12@outlook.com (G.S.) ; \\ dyq8643@gmail.com (Y.D.); hehaihua2002@jhc.edu.cn (H.H.); lguo@zjut.edu.cn (L.G.) \\ * Correspondence: jiazhao@zjut.edu.cn (J.Z.); xnli@zjut.edu.cn (X.L.); Tel.: +86-571-88871565 (J.Z.); \\ $+86-571-88320002$ (X.L.)
}

Received: 4 August 2018; Accepted: 24 August 2018; Published: 27 August 2018

\begin{abstract}
An efficient and stable heterogeneous Zeolite Supported Ionic Liquid Catalyst (IL/CaX) has been explored in acetylene hydrochlorination reaction. The IL/CaX catalyst exhibits excellent space time yields of vinyl chloride (VCM), when compared to the benchmark of Au/C systems. Through characterization and kinetic studies, the reaction follows a two-site mechanism, which is described as the adsorbed hydrogen chloride on the $\mathrm{Ca}^{2+}$ in zeolite, reacting with the adsorbed acetylene on the cation of ionic liquid to form vinyl chloride. The catalytic reaction takes place at the IL/CaX interface, whilst the upper interphase IL/CaX is not active. The deactivation of the catalyst is caused by the dissolving byproducts in the ionic liquid layer, which can be reactivated by a simple vacuum procedure. It is of great significance to study and develop green non-mercury catalysts, in acetylene hydrochlorination.
\end{abstract}

Keywords: zeolite supported ionic liquid catalyst; IL/CaX; $\mathrm{Ca}^{2+}$; acetylene hydrochlorination

\section{Introduction}

Polyvinyl chloride (PVC) is the third most widely used plastic throughout the world [1]. During the past decade, acetylene hydrochlorination dominated approximately $80 \%$ of total PVC production in China, about $40 \%$ global PVC production, due to plentiful and cost-effective coal supplies, but a shortage of oil and gas [2]. In the commercial industrial process, acetylene $\left(\mathrm{C}_{2} \mathrm{H}_{2}\right)$ reacts with hydrogen chloride $(\mathrm{HCl})$ and is catalyzed by the activated carbon-supported $\mathrm{HgCl}_{2}$ catalyst with typically 10-15 wt \% loading [2], which is volatile and toxic to the environment and human health. Thus, in this reaction, the replacement of $\mathrm{HgCl}_{2}$ catalyst for this reaction to an environment-friendly catalyst is necessary with times. Most studies to date have concentrated on $\mathrm{Au} / \mathrm{AC}[3-5], \mathrm{Pd} / \mathrm{AC}[6,7], \mathrm{Ru} / \mathrm{AC}[8,9]$, and Cu/AC [10,11] catalysts to replace Hg/AC catalysts in acetylene hydrochlorination, which result in much better activity and stability. Except for the above non-mercury catalysts, the metal-free catalysts, particularly nitrogen-doped carbon materials, including activated carbon-supported $\mathrm{g}-\mathrm{C}_{3} \mathrm{~N}_{4}$ [12], SiC-nanocomposite carbon materials doped with nitrogen [12], N-doped carbon materials [13], and zeolitic imidazolate framework (ZIF-8) [14] have already been explored in this reaction. However, none of these catalysts have successful commercialization for acetylene hydrochlorination due to the high cost and insufficient lifetime. Interestingly, many of these catalysts follow the Eley-Rideal (ER) mechanism [5,12,15], that is, $\mathrm{HCl}$ reacting with the adsorbed $\mathrm{C}_{2} \mathrm{H}_{2}$ on the active sites to produce vinyl chloride (VCM); and acetylene adsorption is of great importance at the beginning of this reaction. Hutchings et al. [1] proposed 
that the adsorption of acetylene on $\mathrm{AuCl}_{3}$ is relatively stronger than that of hydrogen chloride. The active metallic cations of metal-based catalysts [1] could be reduced by high-energy electron of acetylene and formed non-active metallic particles in hydrochlorination of acetylene [16]. In addition, the strong adsorption capacity of acetylene could oligomerize and then cover the active sites especially, for non-metal catalysts due to the exothermal nature of this reaction $\left(\Delta \mathrm{H}=-124.8 \mathrm{~kJ} \cdot \mathrm{mol}^{-1}\right)$ [17]. Although the stability of the catalysts above can be enhanced by strengthening the adsorption of hydrogen chloride or partly regenerated with the aqua regia [18] or high temperature $\mathrm{NH}_{3}$ treatment [17], it is not sustainable in terms of the strong adsorption of acetylene. Considering all the issues, how to avoid the strong adsorption of acetylene, or design a catalyst with a new reaction mechanism [19], may be a direction for acetylene hydrochlorination.

In our previous work, a highly active supported-Ionic-Liquid-phase (SILP) Au catalyst was first reported for hydrochlorination of acetylene [20,21], the Au-based catalyst showed superior activity and stability after immobilizing a thin ionic liquid film onto activated carbon support on which gold was highly dispersed. At the same time, we also published nitrogen-modified activated carbon supported gold and gold-cesium(I) [22], as highly active and stable catalysts for this reaction. As we know, imidazolium-based ionic liquids consist mainly N-heterocyclic structure, which could be the nitrogen source for metal-free carbon nitride catalyst. Additionally, compared to other well-known activated carbon carriers, the zeolite with unique properties, including unique supercage, high thermal stability, and high surface area, had already been applied as a non-mercury catalyst support for acetylene hydrochlorination [23,24].

In addition to different ways of zeolite and ionic liquid being utilized in this reaction, no report is yet available on the zeolite supported ionic liquid system, taking the advantages of mineral ionic liquids and zeolite, synergistically catalyzing hydrochlorination of acetylene. Furthermore, the supported ionic liquid phase (SILP) catalysts is a fundamental, new approach to transfer the needed catalytic properties of ionic liquid to a porous solid by dispersing a thin film of ionic liquids (ILs) onto the solid. These findings inspired us to systematically study the activity and stability of zeolite CaX supported imidazolium-based ILs 1-ethyl-3-methylimidazolium tetrafluoroborate ([Emim] $\left[\mathrm{BF}_{4}\right]$ ), as catalysts for acetylene hydrochlorination. Based on the evaluation results, kinetic studies and various characterizations, the IL/CaX catalyst exhibited remarkable space time yields of VCM. Furthermore, the effect of the catalytic behavior, active sites, and reaction mechanism were also explored in detail.

\section{Results and Discussion}

\subsection{Catalytic Characterization}

SEM analyses were performed to illustrate the surface morphology of $\mathrm{CaX}$ and IL/CaX. As can be seen from SEM images (Figure 1a), the morphology of CaX zeolite was octahedral geometry, some of them closely coalesce with each other, which was the typical morphology for $\mathrm{X}$ type zeolite (Figure 1a) [25]. After introducing a thin ionic liquid film, the surface of IL/CaX had no obvious change (Figure 1b), compared with the pure CaX. The result indicated that there was no destruction of the CaX zeolite apparent structure, after the ionic liquid immobilization. In addition, the surface of $\mathrm{CaX}$ zeolite was rough, whereas the IL/CaX zeolite had a relatively plain surface. It seemed obvious that the surface of $\mathrm{CaX}$ zeolite had been coated with $[\mathrm{Emim}]\left[\mathrm{BF}_{4}\right]$ successfully and formed an ionic liquid film on it. 

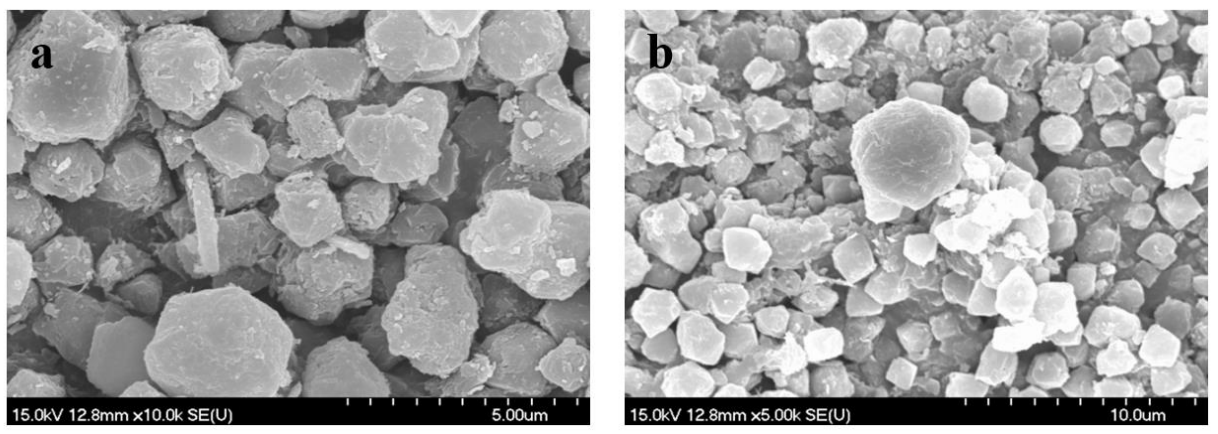

Figure 1. SEM images of: (a) CaX and (b) IL/CaX catalysts.

The isotherm curves for $\mathrm{CaX}$ and IL/CaX resembled the type I isotherms, according to the IUPAC classification, which was characteristic of a microporous structure (Figure 2B) [26]. The surface area of CaX had reduced from 343 to $28 \mathrm{~m}^{2} / \mathrm{g}$, upon anchoring the thin ionic liquid film. The decreases in the BET surface areas of IL/CaX were attributed to the immobilization of ionic liquid on porous CaX, resulting in the block of micropores and decrease of surface areas [27]. The structural properties of the supported ionic liquid on zeolite agreed with the reported values in Reference [28]. This result indicated that $[E m i m]\left[\mathrm{BF}_{4}\right]$ had been successfully supported onto the framework of CaX zeolite. Figure 2B shows the X-ray diffraction patterns (XRD) of $\mathrm{CaX}$ and IL/CaX. The XRD patterns of zeolite CaX had a sharp diffraction at around $2 \theta=6.1^{\circ}$, which was believed to originate from the (111) plane of $\mathrm{CaX}$ zeolite [25]. Furthermore, the reflections at around $23.3^{\circ}$ were located at a position similar to that of the (533) plane of CaX zeolite, although its intensity in zeolite was much weaker than the (111) plane. In comparison to the pure CaX, the diffraction pattern for IL/CaX was almost the same, which implied that the original crystal structure was not significantly affected after immobilization an ionic liquid layer on zeolite. However, the relative intensity of (111) peak was lower than that of CaX. This could be attributed to the disordering of the porous structure and variation the electron density (especially for the major peak at $2 \theta=6.1^{\circ}$ ), due to immobilization of an ionic liquid layer onto zeolite $[27,28]$. These results agreed well with the SEM analyses.

A

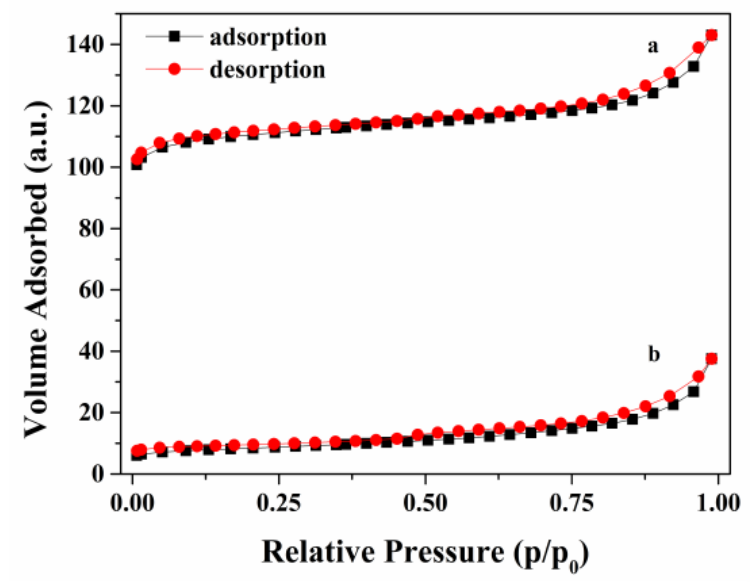

B

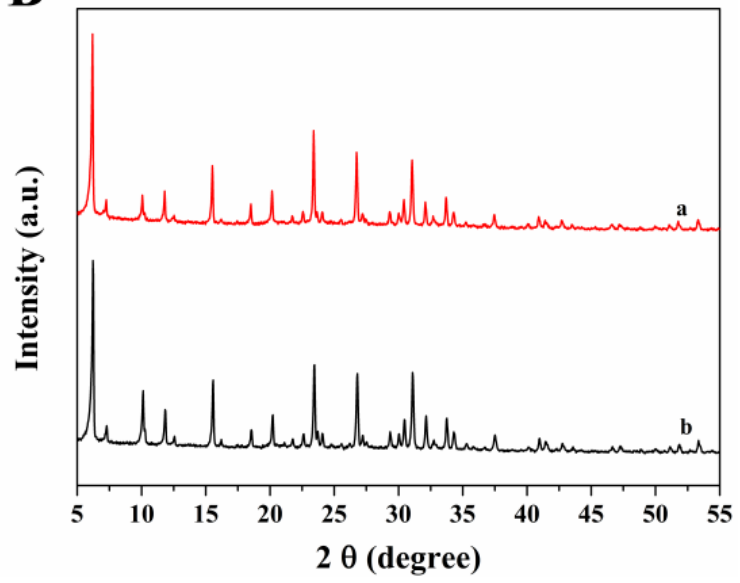

Figure 2. (A) Nitrogen adsorption-desorption isotherms and (B) X-ray diffraction patterns (XRD) patterns of (a) CaX, (b) IL/CaX.

Thermal gravimetric analysis (TGA) was performed to monitor the thermal stability of CaX and IL/CaX (Figure 3). Both the CaX and IL/CaX presented a slight weight loss in the range of 50-200 ${ }^{\circ} \mathrm{C}$ due to the desorption of physiosorbed water and other pre-adsorbed gases, due to exposure 
to atmosphere during the synthesis steps existing on the catalysts. Subsequently, a significant weight loss at $200-310{ }^{\circ} \mathrm{C}$ was attributed to the loss of surface silanol groups for CaX [28]. However, when ionic liquid immobilized onto $\mathrm{CaX}$, the loss temperature of silanol groups was increased to $430{ }^{\circ} \mathrm{C}$, and the decomposition temperature for supported $[\mathrm{Emim}]\left[\mathrm{BF}_{4}\right]$ was $551^{\circ} \mathrm{C}$. For pure $[\mathrm{Emim}]\left[\mathrm{BF}_{4}\right]$, the decomposition temperature was $412{ }^{\circ} \mathrm{C}[29,30]$. This result suggested that there must be a strong bonding between ILs and the zeolite surface, which could be responsible for such behavior and the different characteristics of IL/CaX samples, compared to either individual components. Furthermore, the strong interaction, probably the interface between ionic liquid and zeolite, was favorable for catalytic performance (this would be discussed after the reactivity results are presented). This was also indirect evidence of the successful immobilization of $[\mathrm{Emim}]\left[\mathrm{BF}_{4}\right]$ on $\mathrm{CaX}$ zeolite.

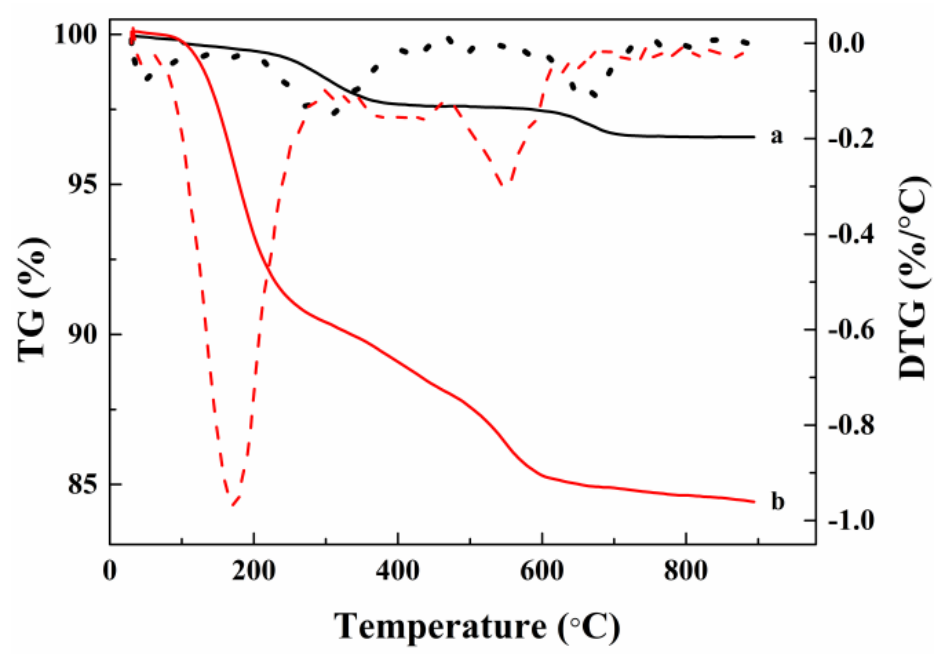

Figure 3. Thermal gravimetric analysis (TGA) and DTG curves of: (a) CaX (black), (b) IL/CaX (red).

With an aim to reveal the interaction forces of [Emim] $\left[\mathrm{BF}_{4}\right]$ and CaX zeolite, FTIR measurements were carried out (Figure 4). The CaX (a) exhibited a sharp band at $1630 \mathrm{~cm}^{-1}$ and a broad band at $3450 \mathrm{~cm}^{-1}$, which could be attributed to the $\mathrm{Si}-\mathrm{OH}$ stretching vibration and the $\mathrm{H}-\mathrm{O}-\mathrm{H}$ stretching mode of adsorbed water. The characteristic peaks at 462,759 , and $989 \mathrm{~cm}^{-1}$ were the Si-O vibrations of zeolite [31,32]. For [Emim] [BF 4 (c), the IR bands between 2700 and $3200 \mathrm{~cm}^{-1}$ were attributed to $\mathrm{C}-\mathrm{H}$ stretching vibrations of the imidazolate ring. Bands at 1570 and $1461 \mathrm{~cm}^{-1}$ were due to the stretching vibration of the imidazolate framework; and the spectral IR bands obtained at around 1169 $\mathrm{cm}^{-1}$ IR band were attributed to C-H rocking vibrations of the imidazolate ring [33]. For IL/CaX (b), it exhibited the same, but broader characteristic bands of the - $\mathrm{OH}$ stretching mode of adsorbed water (1630 and $\left.3450 \mathrm{~cm}^{-1}\right)$, due to the hygroscopic nature of [Emim] $\left[\mathrm{BF}_{4}\right]$ [34]. In addition, the characteristic band of imidazolate ring (2700-3200 $\mathrm{cm}^{-1}$ and $\left.1461-1570 \mathrm{~cm}^{-1}\right)$ corresponding to the IL were also observed for IL/CaX (b), which indicated that the $[\mathrm{Emim}]\left[\mathrm{BF}_{4}\right]$ was successfully immobilized onto the $\mathrm{CaX}$ zeolite. Moreover, IL/CaX showed a small shift for the -OH stretching of zeolite. The band at $1630 \mathrm{~cm}^{-1}$ was blue-shifted by $10 \mathrm{~cm}^{-1}$ and the band at $3450 \mathrm{~cm}^{-1}$ was red-shifted by $21 \mathrm{~cm}^{-1}$. The IR spectral bands at 2884 and $2951 \mathrm{~cm}^{-1}$ corresponded to the asymmetric C-H stretching vibrations of the cation alkane group of [Emim] $\left[\mathrm{BF}_{4}\right]$ and were also red-shifted by 38 and $28 \mathrm{~cm}^{-1}$, respectively [35]. This suggested that the acidity of silanols, and their ability to interact with molecules on the surface via $\mathrm{H}$-bonding, electrostatic interaction, and so on, between - $\mathrm{OH}$ of silica and alkyl side chain of ionic liquid, may result in structural orientations of the cation and the anion. Similar observation was reported in the previous study published by Henni et al. [35]. 


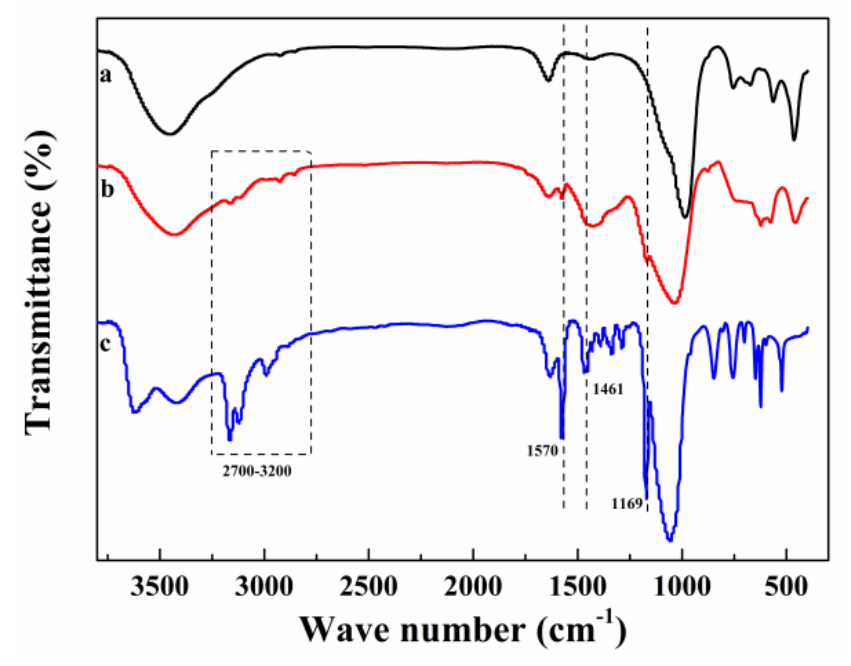

Figure 4. FT-IR spectra of: (a) $\mathrm{CaX}$, (b) IL/CaX, (c) $[\mathrm{Emim}]\left[\mathrm{BF}_{4}\right]$.

\subsection{Catalytic Performance}

Figure $5 \mathrm{a}$ shows that the IL/CaX catalyst was more active at higher temperatures. The acetylene conversion of IL/CaX was increased with the temperature rising from 200 to $360{ }^{\circ} \mathrm{C}$. The results implied that IL/CaX exhibited unique and superior reactivity at high temperatures. However, with the continued rising of reaction temperature, no obvious increase in conversion rate had been observed, which indicated that $320{ }^{\circ} \mathrm{C}$ was the optimal reaction temperature with a nearly $90 \%$ acetylene conversion, and VCM selectivity more than $95 \%$. Figure $5 \mathrm{~b}$ shows the catalytic performance of $\mathrm{IL} / \mathrm{CaX}, \mathrm{CaX}$, and IL at a reaction temperature of $320^{\circ} \mathrm{C}$, respectively. Although the $\operatorname{GHSV}\left(\mathrm{C}_{2} \mathrm{H}_{2}\right)$ of IL/CaX was nearly five times as much, as pure CaX and IL, IL/CaX still showed the highest acetylene conversion. During the test time of $300 \mathrm{~min}$ on stream, no obvious deactivation was observed, which indicated higher catalytic activity and stability over IL/CaX, than pure CaX and IL catalysts. By analyzing the results of catalyst characterization above (Figures 1-4), this was likely to be the synergistic effect between ionic liquid ([Emim] $\left.\left[\mathrm{BF}_{4}\right]\right)$ and $\mathrm{CaX}$ zeolite. Space-time yields were a universal parameter to measure catalytic performance [36]. We calculated the space-time yields of some novel catalysts $[1,12,15,18,20,37-43]$, for acetylene hydrochlorination and selected gold catalysts, as a benchmark (Figure 5c). The space time yields of $\mathrm{VCM}$ for $\mathrm{Au} / \mathrm{C}$ [19], $\mathrm{Au}\left(\mathrm{Na}_{3} \mathrm{Au}\left(\mathrm{S}_{2} \mathrm{O}_{3}\right)_{2}\right) / \mathrm{C}$ [1], $\mathrm{Au}-\mathrm{IL} / \mathrm{AC}$ [20], and IL/CaX were $0.9,1.3,2.1$, and $0.75 \mathrm{~kg} \mathrm{VCM} /(\mathrm{kg}$ catalyst $\mathrm{h}$ ), respectively. It was clear that IL/CaX showed superior performance among the non-gold-based systems. Compared with the benchmark of gold-based catalysts, IL/CaX still exhibited excellent catalytic performance.

\subsection{Catalytic Active Sites and Reaction Mechanism}

To provide further insight into the possible catalytic mechanism of acetylene hydrochlorination, we have systematically studied the preliminary kinetic evaluation of this reaction. The activation energy (Ea) were calculated based on the Arrhenius plots $(\ln (R)$ versus $1000 / T)$, illustrated in Figure 6a. The straight line showed that the mass transfer limitations were negligible [44], which verified that the catalysis of IL/CaX for acetylene hydrochlorination was a kinetics-controlled process. The slope was observed at IL/CaX catalyst, corresponding to an Ea-IL/CaX $=84 \mathrm{~kJ} / \mathrm{mol}$, which might explain why IL/CaX showed superior activity under high temperature conditions (Figure 5a). In addition, the reaction obeyed 0.58 order for $\mathrm{HCl}$ and 0.54 order for $\mathrm{C}_{2} \mathrm{H}_{2}$, which suggested that the reaction might be related to a two-site mechanism (Figure 6b), as described in Reference [45]. Pretreatment experiments of catalyst by reaction gas $\left(\mathrm{C}_{2} \mathrm{H}_{2}\right.$ and $\left.\mathrm{HCl}\right)$ showed that no obvious changed had been observed during this procedure, which further supported that the adsorption sites of $\mathrm{C}_{2} \mathrm{H}_{2}$ and $\mathrm{HCl}$ might be different (Figure 5d). 

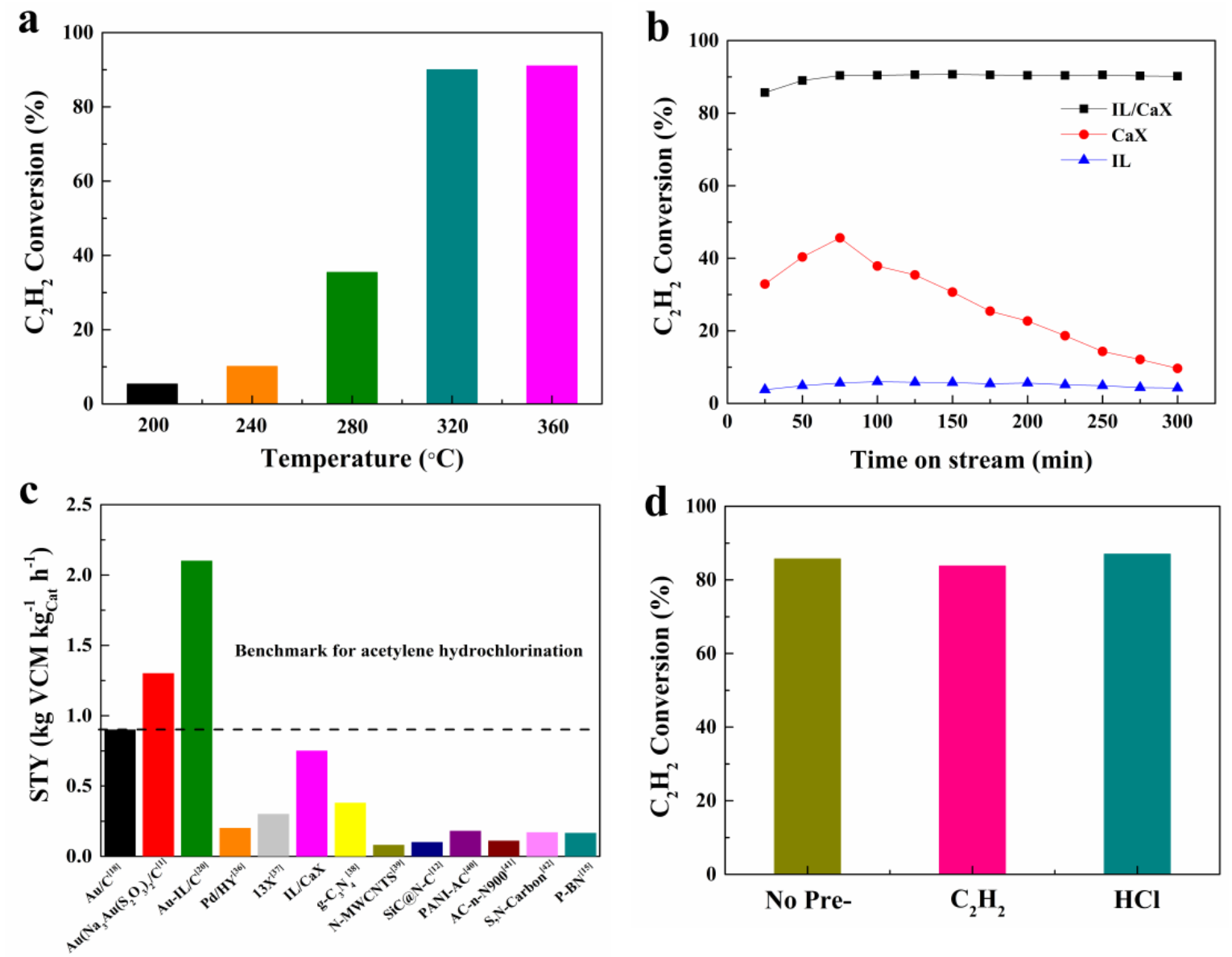

Figure 5. Catalytic performance as functions of different parameters: (a) Reaction temperature of IL/CaX; (b) Different catalysts. Reaction conditions: IL/CaX, $320{ }^{\circ} \mathrm{C}, \mathrm{GHSV}\left(\mathrm{C}_{2} \mathrm{H}_{2}\right)=100 \mathrm{~h}^{-1}$; $\mathrm{V}(\mathrm{HCl}) / \mathrm{V}\left(\mathrm{C}_{2} \mathrm{H}_{2}\right)=1.2 ; \mathrm{CaX}, 32{ }^{\circ} \mathrm{C}, \mathrm{GHSV}\left(\mathrm{C}_{2} \mathrm{H}_{2}\right)=20 \mathrm{~h}^{-1} ; \mathrm{V}(\mathrm{HCl}) / \mathrm{V}\left(\mathrm{C}_{2} \mathrm{H}_{2}\right)=1.2 ; \mathrm{IL}, 320{ }^{\circ} \mathrm{C}$, $\operatorname{GHSV}\left(\mathrm{C}_{2} \mathrm{H}_{2}\right)=20 \mathrm{~h}^{-1}$; and $\mathrm{V}(\mathrm{HCl}) / \mathrm{V}\left(\mathrm{C}_{2} \mathrm{H}_{2}\right)=1.2$; (c) Space-time yield of VCM, STY $(\mathrm{VCM})$, between the catalysts developed in this work and others'. Calculated for $240 \mathrm{~min}$ of reaction; (d) Different pretreatment: No pretreatment, $\mathrm{C}_{2} \mathrm{H}_{2}$ pretreatment and $\mathrm{HCl}$ pretreatment.

Temperature-programmed desorption-mass spectrometry (TPD-MS) reflected the adsorption property of $\mathrm{C}_{2} \mathrm{H}_{2}$ and $\mathrm{HCl}$ on IL/CaX (Figure $7 \mathrm{a}-\mathrm{c}$ ). The adsorption of $\mathrm{C}_{2} \mathrm{H}_{2}$ on the $\mathrm{CaX}$ and IL/CaX showed polarization, whilst $\mathrm{C}_{2} \mathrm{H}_{2}$ was scarcely adsorbed on pure $\mathrm{CaX}$, compared with the $\mathrm{C}_{2} \mathrm{H}_{2}$ adsorption on IL/CaX (Figure 7a). The difference might be caused by the supported ILs. It was reported that imidazolium-based ionic liquids with $\mathrm{N}$-heterocyclic structure, could be the nitrogen source for metal-free carbon nitride catalyst, and numerous studies have already indicated that the high solubility of $\mathrm{C}_{2} \mathrm{H}_{2}$ in ionic liquid through the formation of $\mathrm{C}_{2} \mathrm{H}_{2}-\mathrm{Im}^{+}$complex [46]. In addition, the acetylene-metal bond was a combination of $\mu$ - and $\pi$ - bonding [3]. Therefore, the attack of this type complex as an electrophilic agent to triple bond of acetylene did not take place the $\mathrm{Ca}^{2+}$ in the zeolite framework due to the standard electrode potential of $\mathrm{Ca}^{2+}(-2.868 \mathrm{eV})$ [47]. It meant that $\mathrm{Ca}^{2+}$ was chemical inertness in the reductive gas, $\mathrm{C}_{2} \mathrm{H}_{2}$. This was consistent with Hutchings' work [1,47]. According to the HCl-TPD-MS profile shown in Figure 7b, only one $\mathrm{HCl}$ desorption peak was observed for CaX catalyst. The special basicity arising from $\mathrm{Ca}^{2+}$ in the zeolite framework might promote the adsorption of $\mathrm{HCl}$ [46]. Subsequently, we systematically investigated zeolites catalysts with different loading calcium cations by zeolite impregnation with calcium chloride solution. The exact chemical composition was determined by XRF analysis, which revealed that the exchange of $\mathrm{Na}^{+}$by $\mathrm{Ca}^{2+}$ in zeolite, occurred during the process of reimpregnation (Figure $6 \mathrm{c}$ ). Although the 
intensity of the diffraction peaks decreased slightly, the original crystal structure of CaX zeolite was not destroyed during this process (Figure S1). In addition, no XRD patterns have been found for the $\mathrm{CaF}_{2}$, which suggested that the $\mathrm{BF}_{4}$ of $[\mathrm{Emim}]\left[\mathrm{BF}_{4}\right]$ did not remain in the zeolite. The evaluation of catalyst after loading ionic liquid ([Emim] $\left[\mathrm{BF}_{4}\right]$ ) showed that the conversion rate increased with increasing the mass of calcium (Figure 7d). Although the amount of $\mathrm{Na}^{+}$in the zeolite was much higher than that of $\mathrm{Ca}^{2+}, \mathrm{Na}^{+}$did not play a catalytic role in the hydrochlorination of acetylene. This result preliminarily explained the important influence of calcium ions in zeolite on the reaction. The absorption concentration of $\mathrm{HCl}$ with calcium silicate was at $1.4 \mathrm{~mol} / \mathrm{mol} \mathrm{of} \mathrm{Ca}^{2+}$, which had already been reported in the literature, according to Reference [46]. Further, the activation of the $\mathrm{H}-\mathrm{Cl}$ bond had already associated with the acetylene hydrochlorination catalytic performance [19]. According to this information, the two peaks at 570 and $634 \mathrm{~K}$, were the chemical adsorption of $\mathrm{HCl}$ on $\mathrm{Ca}^{2+}$ for $\mathrm{CaX}$ and IL/CaX, respectively (Figure $7 \mathrm{~b}$ ). The $\mathrm{HCl}$ desorption peak of IL/CaX at a lower temperature $361 \mathrm{~K}$, was the physical adsorption $\mathrm{HCl}$ in supported ionic liquid layer [48].

$\mathbf{a}$

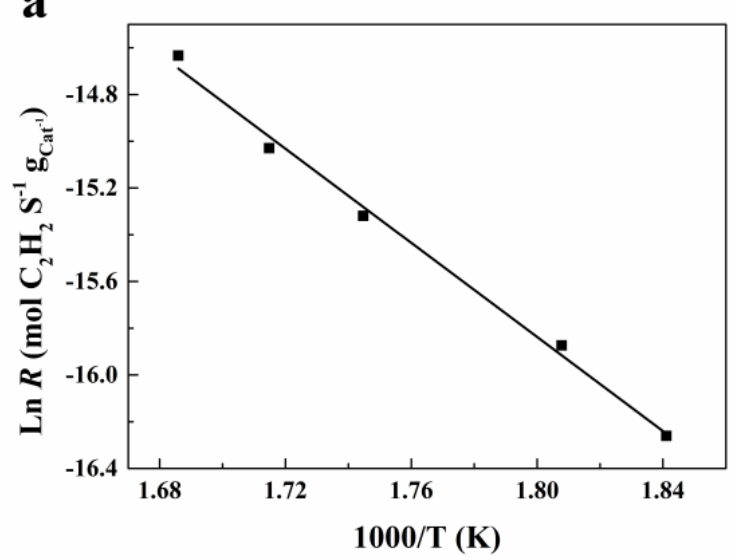

c

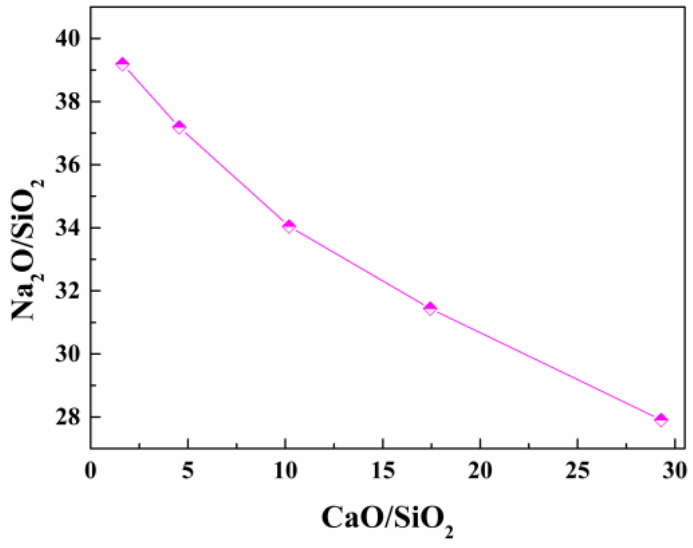

b

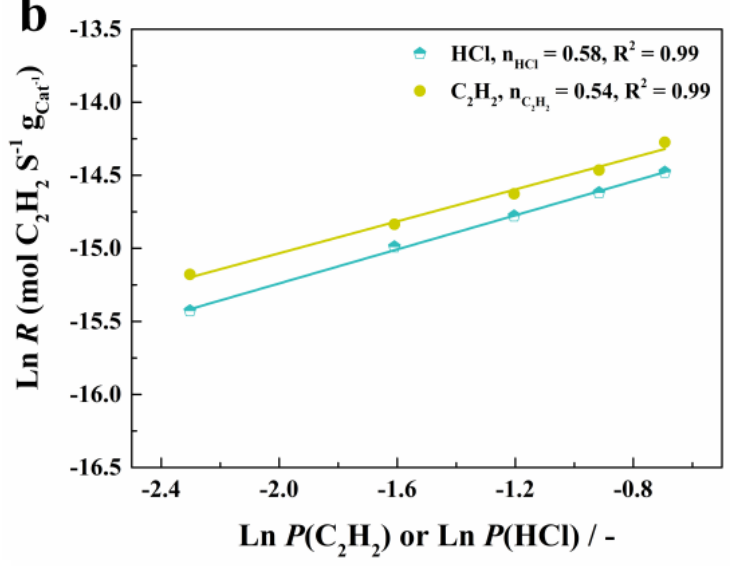

d

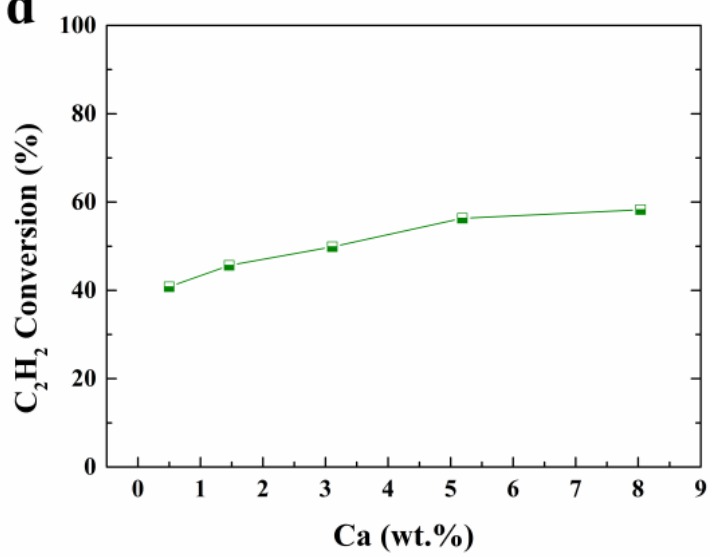

Figure 6. (a) Activation energy (Ea). Arrhenius plot for the initial rate LnR and 1000/T. R denotes for the moles of VCM formation on $1 \mathrm{~g}$ catalyst in one second; (b) Reaction orders for $\mathrm{HCl}$ and $\mathrm{C}_{2} \mathrm{H}_{2}$ over IL/CaX (Calculated at $<15 \%$ conversion of acetylene); (c) Mass change of $\mathrm{Na}_{2} \mathrm{O}$ to $\mathrm{CaO}$ in zeolite; (d) Acetylene conversion of IL/CaX as a function of Ca loading. Reaction conditions: $320^{\circ} \mathrm{C}$, $\operatorname{GHSV}\left(\mathrm{C}_{2} \mathrm{H}_{2}\right)=300 \mathrm{~h}^{-1} ; \mathrm{V}(\mathrm{HCl}) / \mathrm{V}\left(\mathrm{C}_{2} \mathrm{H}_{2}\right)=1.2$. 
a

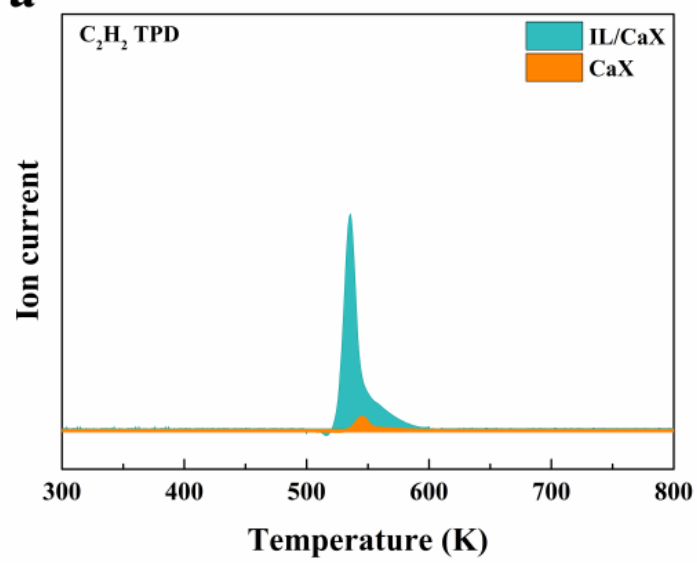

c

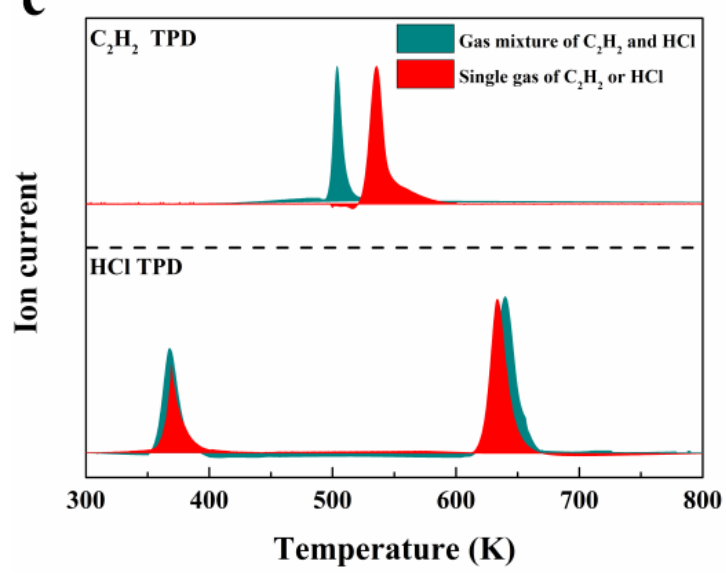

b

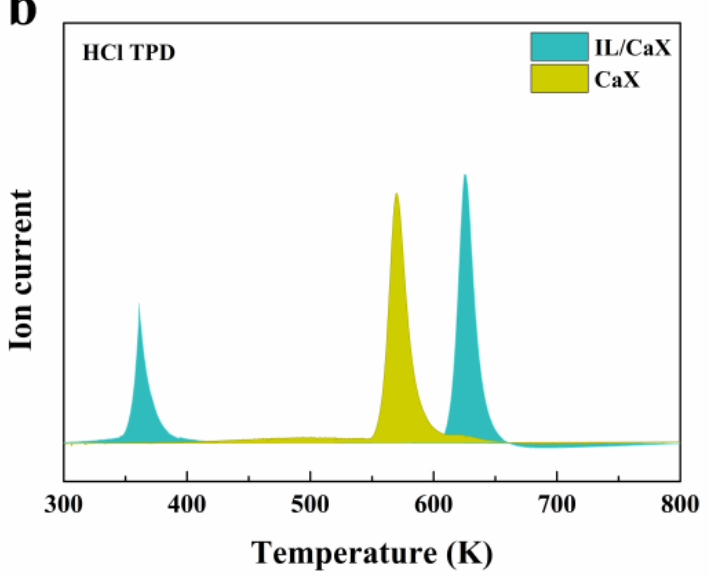

d

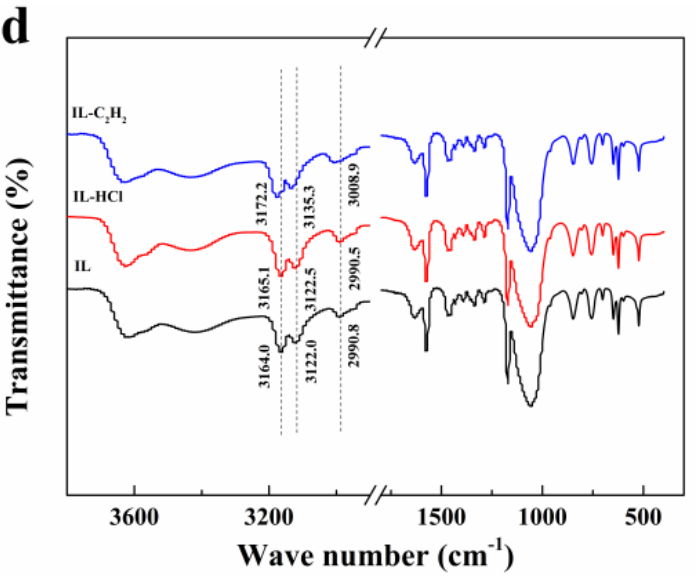

Figure 7. (a) $\mathrm{C}_{2} \mathrm{H}_{2}$-TPD-MS; (b) HCl-TPD-MS; (c) Gas mixture of $\mathrm{C}_{2} \mathrm{H}_{2}$ and $\mathrm{HCl}$ TPD-MS; (d) Infrared spectra of $[\mathrm{Emim}]\left[\mathrm{BF}_{4}\right],[\mathrm{Emim}]\left[\mathrm{BF}_{4}\right]-\mathrm{HCl}$, [Emim] $\left[\mathrm{BF}_{4}\right]-\mathrm{C}_{2} \mathrm{H}_{2}$.

To our knowledge, the area of desorption peak represented the amount of adsorbed species, and desorption temperature reflected adsorption capacity [49]. The $\mathrm{HCl}$ desorption temperature and peak area of IL/CaX were higher than pure $\mathrm{CaX}$, which indicated that the adsorption property of $\mathrm{HCl}$ on IL/CaX was much stronger. The $\mathrm{C}_{2} \mathrm{H}_{2}$ and $\mathrm{HCl}$ desorption peaks area of gas mixture of $\mathrm{C}_{2} \mathrm{H}_{2}$ and $\mathrm{HCl}$ from IL/CaX and that of pure $\mathrm{C}_{2} \mathrm{H}_{2}$ (Figure 7a) and $\mathrm{HCl}$ (Figure $7 \mathrm{~b}$ ), were almost unchanged compared to the pure $\mathrm{C}_{2} \mathrm{H}_{2}$ (Figure 7a) and $\mathrm{HCl}$ desorption peaks (Figure $7 \mathrm{~b}$ ). This may have implied that the $\mathrm{C}_{2} \mathrm{H}_{2}$ and $\mathrm{HCl}$ might be adsorbed at different sites (Figure 7c). This was consistent with the above kinetic study (Figure $6 \mathrm{~b}$ ) and reaction gas pretreatment experiments (Figure $5 \mathrm{~d}$ ). Furthermore, the $\mathrm{HCl}$ desorption peak at $634 \mathrm{~K}$ shifted to $638 \mathrm{~K}$, and the peak at $369 \mathrm{~K}$ shifted to $367 \mathrm{~K}$. The $\mathrm{C}_{2} \mathrm{H}_{2}$ desorption peak at $534 \mathrm{~K}$ shifted to $503 \mathrm{~K}$. The lower desorption temperature of acetylene in the presence of mixed gas $\left(\mathrm{C}_{2} \mathrm{H}_{2}\right.$ and $\left.\mathrm{HCl}\right)$ experiments, implied that the adsorbed $\mathrm{HCl}$ on $\mathrm{Ca}^{2+}$ may have further activated the adsorbed $\mathrm{C}_{2} \mathrm{H}_{2}$ on the ionic liquids.

FTIR results further proved that $\mathrm{HCl}$ did not induce any change of IR signals, compared with the pure [Emim] $\left[\mathrm{BF}_{4}\right]$ (Figure $7 \mathrm{~d}$ ). However, with introduction of $\mathrm{C}_{2} \mathrm{H}_{2}$ to $[\mathrm{Emim}]\left[\mathrm{BF}_{4}\right]$, the largest shift occurred at $2990.8,3122.0$, and $3164.0 \mathrm{~cm}^{-1}$ bands. The bands at $2990.8 \mathrm{~cm}^{-1}$ were blue-shifted by $18.1 \mathrm{~cm}^{-1}, 3122.0 \mathrm{~cm}^{-1}$ by $13.3 \mathrm{~cm}^{-1}$, and $3164.0 \mathrm{~cm}^{-1}$ by $8.2 \mathrm{~cm}^{-1}$. The peaks at $2990.8,3122.0$, and $3164.0 \mathrm{~cm}^{-1}$ were the stretching vibration of $\mathrm{C}(2)-\mathrm{H}, \mathrm{C}(5)-\mathrm{H}$, and $\mathrm{C}(4)-\mathrm{H}$ of [Emim] cation, respectively [33]. The largest shifts detected for the $\mathrm{C}(2)-\mathrm{H}$ vibrations implied the strong interaction between the $\mathrm{C}(2)-\mathrm{H}$ of $[\mathrm{Emim}]$ cation and $\mathrm{C}_{2} \mathrm{H}_{2}$. Based on the kinetic studies, TPD and infrared spectra, we speculated that the reaction may probably proceed via a two-site mechanism, in which the adsorbed hydrogen chloride on $\mathrm{Ca}^{2+}$ in zeolite reacted with the adsorbed acetylene on cation of 
ionic liquid to form vinyl chloride. In addition, the adsorbed $\mathrm{HCl}$ on $\mathrm{Ca}^{2+}$ may further activate the adsorbed $\mathrm{C}_{2} \mathrm{H}_{2}$.

To further deepen the understanding of the reaction mechanism, DFT calculations were needed to combine both the experimental and characteristic results. The surface and interface properties, such as the liquid/solid interface with the support material have received increasing attention. The zeolite materials were worked as the ligands to chemical fixation of the cations of [Emim] $\left[\mathrm{BF}_{4}\right]$, and the alkyl chains of the cations extended into the out surface of the bulk liquid layer [50,51]. With the loading of [Emim] $\left[\mathrm{BF}_{4}\right]$ from $5 \%$ to $30 \%$, the thermal decomposition of the IL was similar to the pure ionic liquid, which was not or only slightly altered by the support (Figure S2) and little change was found for the yield of vinyl chloride (Figure S3). This phenomenon indicated that the IL/CaX interface might be active at the beginning of the reaction, whilst the upper interphase of IL/CaX were not active. The thickness of ionic liquid layer for IL/CaX catalyst could be estimated to $1.1 \mathrm{~nm}$ (calculated from a correlation by Haumann et al. [52]), which was comparable with a monolayer thickness. This value was in good agreement with the observation by the reported literature, in Reference [53]. Furthermore, the decomposition temperature and the chemical bands of $[\mathrm{Emim}]\left[\mathrm{BF}_{4}\right]$ results had already implied the strong interaction between IL and zeolite, at the interface of IL/CaX. Furthermore, only the IL/CaX showed the highest catalytic performance, compared with the pure CaX and IL catalysts. Combined with the two-site mechanism and the structure orientation of $[\mathrm{Emim}]\left[\mathrm{BF}_{4}\right]$ on the surface of zeolite, we could speculate that the reaction may have occurred at the interface between $\mathrm{CaX}$ and $[\mathrm{Emim}]\left[\mathrm{BF}_{4}\right]$ ionic liquid layer with $1.1 \mathrm{~nm}$ region. This revealed that acetylene hydrochlorination may have been an interfacial reaction over IL/CaX.

\subsection{Deactivation and Regeneration Studies}

To reveal the deactivation and regeneration mechanism of IL/CaX, a higher GHSV $\left(\mathrm{C}_{2} \mathrm{H}_{2}\right)$ of approximately $300 \mathrm{~h}^{-1}$ was chosen to evaluate it (Figure S4). Figure 8 presents the reduction of $\mathrm{C}_{2} \mathrm{H}_{2}$ conversion of IL/CaX catalyst from $46.5 \%$ to $16.3 \%$, after running for $200 \mathrm{~min}$, whereas, surprisingly, the VCM selectivity remained constant nearly $95 \%$. This interesting phenomenon enabled us to conjecture, that the dissolved byproducts in ionic liquid layer may be the cause of the catalytic deactivation. To demonstrate the above hypothesis, we designed the following experiments. Firstly, the feed gases were cut-off after the IL/CaX catalyst had been evaluated for $200 \mathrm{~min}$ (Figure 8). Then, the reactor with the used IL/CaX catalyst was dried under vacuum for $60 \mathrm{~min}$, at $120^{\circ} \mathrm{C}$. The vacuum treatment gases were analyzed by gas chromatography. 1,2-dichloroethane and 1, 1-dichloroethane were detected and confirmed by injection of the respective pure compounds as references. In general, the oligomeric acetylene species were the common reason for the deactivation of carbon-based catalysts, which would hinder the access of reactants to the active sites, leading to a lowered activity. However, the oligomeric acetylene species were not detected in our experiments. Finally, the reaction was recovered under the same conditions as previous. The activity of the regenerated catalyst was partly recovered, and the highest acetylene conversion was slightly lower than the initial level. With this method, the catalyst could be recycled for four runs (Figure 8). To further study the deactivation mechanism of the catalyst, the deactivated catalyst, Used-IL/CaX, was treated with acetylene and hydrogen chloride for an hour, respectively. Then TPD-MS was recorded to determine the adsorption and desorption properties of the reactants. As shown in Figure S5, the $\mathrm{HCl}$-desorption peak area of deactivated IL/CaX catalyst was a little lower than that of fresh IL/CaX, whilst the adsorption of acetylene was greatly reduced. Therefore, with the by-products gradually dissolved in the ionic liquid layer, the adsorption amount of acetylene was sharply reduced, which was the main reason that led to the catalyst deactivation. The result confirmed the interpretation, that the gradual deactivation of the IL/CaX catalyst was attributed to the dissolution of side products in ionic liquid layer. 


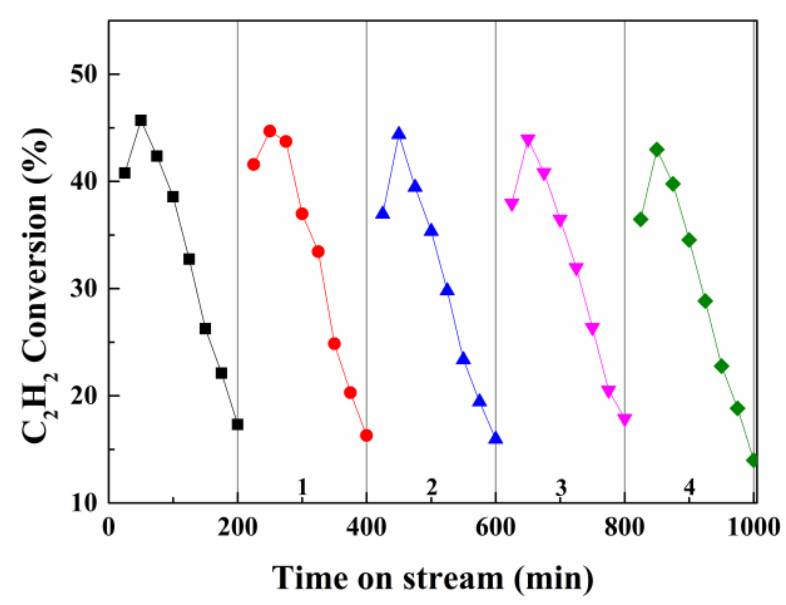

Figure 8. Durability and activity for acetylene hydrochlorination of the fresh and the regenerated IL/CaX catalysis, for 4 cycles. Reaction conditions: $320^{\circ} \mathrm{C}, \mathrm{GHSV}\left(\mathrm{C}_{2} \mathrm{H}_{2}\right)=300 \mathrm{~h}^{-1} ; \mathrm{V}(\mathrm{HCl}) / \mathrm{V}\left(\mathrm{C}_{2} \mathrm{H}_{2}\right)=1.2$.

\section{Materials and Methods}

\subsection{Catalyst Preparation}

The Zeolite Supported Ionic Liquid Catalysts were prepared via an incipient wetness impregnation technique. Firstly, 1-ethyl-3-methylimidazolium tetrafluoroborate ([Emim] $\left.\left[\mathrm{BF}_{4}\right]\right)$, (Lanzhou Greenchem ILS, LICP. CAS, Lanzhou, China) was dissolved in deionized water. Then, zeolite CaX (Aladdin Industrial Corporation, Shanghai, China) was added to the IL-containing solution and mixed uniformly. Subsequently, the impregnated sample was laid overnight. Finally, the sample was dried at $120^{\circ} \mathrm{C}$, for $16 \mathrm{~h}$, under nitrogen flow to obtain the catalyst, labeled as IL/CaX with a nominal total ionic liquid loading of $5 \mathrm{wt} \%$.

\subsection{Catalytic Reaction Evaluation}

The catalytic performance was determined in a fixed-bed micro-reactor (10 $\mathrm{mm}$ diameter). After the catalyst was loaded into the reactor, the reactor was heated up to the reaction temperature at a ramp rate of $10{ }^{\circ} \mathrm{C} / \mathrm{min}$ and held for $30 \mathrm{~min}$ under nitrogen atmosphere. Then, the $\mathrm{C}_{2} \mathrm{H}_{2} / \mathrm{HCl}$ mixed gas was fed into the reactor under ambient pressure. The effluent gas mixture from the reactor was sent through a bubbler containing aqueous sodium hydroxide solution to neutralize the free hydrogen chloride, then analyzed using gas chromatography.

\subsection{Characterization of Catalysts}

SEM morphology were evaluated with a Philips XL-30 scanning electron microscope. Nitrogen adsorption/desorption isotherms was performed using a Micromeritics ASAP 2020 instrument. X-ray diffraction (XRD) measurements were obtained using a PANalytical-X'Pert PRO generator with $\mathrm{Cu}$ $\mathrm{K} \alpha$ radiation $(\lambda=0.1541 \mathrm{~nm})$ operating at $60 \mathrm{kV}$ and $55 \mathrm{~mA}$. Thermogravimetric analysis (TGA) was recorded on a NETZSCH STA 449C Jupiter instrument in the temperature range from 30 to $900{ }^{\circ} \mathrm{C}$, at the rate of $10^{\circ} \mathrm{C} / \mathrm{min}$, with an $\mathrm{N}_{2}$ flow of $20 \mathrm{~mL} / \mathrm{min}$. FT-IR characterizations were performed on a Nicolet 6700. The TPD-MS curves of reactants was performed on an Omnistar GSD320 mass spectrometer.

\section{Conclusions}

This paper reported a novel efficient zeolite supported ionic liquid catalysts, for the hydrochlorination of acetylene. This catalyst exhibited considerable space time yields of VCM, although it was somewhat lower than the benchmark of $\mathrm{Au} / \mathrm{C}$ systems. The enhanced catalytic activity and stability of IL/CaX, might be derived from the association between the zeolite and the ionic liquid. Calcium cations in 
zeolite and N-heterocyclic structure in imidazolium-based ionic liquids, might be the active sites for acetylene hydrochlorination. Kinetic study and characterizations suggested that the reaction might be related to a two-site mechanism. The side products constantly dissolved in ionic liquid layer, which was the main reason for deactivation of IL/CaX. Additionally, the regeneration of the IL/CaX catalyst could be reached using simple vacuum operation. Therefore, IL/CaX is a promising candidate for efficient and green non-mercury catalysts, in vinyl chloride synthesized from acetylene.

Supplementary Materials: The following are available online at http:/ /www.mdpi.com/2073-4344/8/9/351/s1, Figure S1: XRD patterns of $\mathrm{CaX}$ as a function of the amount of $\mathrm{Ca}$ loading: (a) CaX, (b) CaX-1.46 wt \% Ca, (c) CaX-3.11 wt \% Ca, (d) CaX-5.19 wt \% Ca, (e) CaX-8.04 wt \% Ca, Figure S2: The decomposition temperature of [Emim][BF4] with different amount of supporting IL, Figure S3: Space-time yields of VCM with different supporting ILs catalysts, Figure S4: Catalytic performance as functions of different GHSV $\left(\mathrm{C}_{2} \mathrm{H}_{2}\right)$ for IL/CaX. Reaction conditions: $320^{\circ} \mathrm{C} ; \mathrm{V}(\mathrm{HCl}) / \mathrm{V}\left(\mathrm{C}_{2} \mathrm{H}_{2}\right)=1.2$, Figure S5: TPD-MS profiles of $\mathrm{HCl}$ and $\mathrm{C}_{2} \mathrm{H}_{2}$ on the fresh and used IL/CaX catalysts.

Author Contributions: B.W., J.Z. and X.L. conceived and designed the experiments; B.W. and H.L. performed the experiments; B.W., G.S., Y.Y., H.H., Y.D. and L.G. contributed reagents/materials/analysis tools; B.W. wrote the paper.

Funding: Financial support supported by the National Natural Science Foundation of China (NSFC; Grant $21606199,21476207)$ is gratefully acknowledged.

Conflicts of Interest: The authors declare no conflict of interest.

\section{References}

1. Johnston, P.; Carthey, N.; Hutchings, G.J. Discovery, development, and commercialization of gold catalysts for acetylene hydrochlorination. J. Am. Chem. Soc. 2015, 137, 14548-14557. [CrossRef] [PubMed]

2. Zhong, J.W.; Xu, Y.P.; Liu, Z.M. Heterogeneous non-mercury catalysts for acetylene hydrochlorination: Progress, challenges, and opportunities. Green Chem. 2018, 20, 2412-2427. [CrossRef]

3. Hutchings, G. Vapor phase hydrochlorination of acetylene: Correlation of catalytic activity of supported metal chloride catalysts. J. Catal. 1985, 96, 292-295. [CrossRef]

4. Zhao, J.; Wang, B.L.; Xu, X.L.; Yu, Y.; Di, S.X.; Xu, H.; Zhai, Y.Y.; He, H.H.; Guo, L.L.; Pan, Z.Y.; et al. Alternative solvent to aqua regia to activate $\mathrm{Au} / \mathrm{AC}$ catalysts for the hydrochlorination of acetylene. J. Catal. 2017, 350, 149-158. [CrossRef]

5. Zhao, J.; Wang, B.L.; Yue, Y.X.; Di, S.X.; Zhai, Y.Y.; He, H.H.; Sheng, G.F.; Lai, H.X.; Zhu, Y.H.; Guo, L.L.; et al. Towards a greener approach for the preparation of highly active gold/carbon catalyst for the hydrochlorination of ethyne. J. Catal. 2018, 365, 153-162. [CrossRef]

6. Mitchenko, S.A.; Krasnyakova, T.V.; Zhikharev, I.V. Effect of mechanicochemical treatment on the activity of $\mathrm{K}_{2} \mathrm{PdCl}_{4}$ in the heterogeneous catalytic hydrochlorination of acetylene. Theor. Exp. Chem. 2010, 46, 32-38. [CrossRef]

7. Krasnyakova, T.V.; Nikitenko, D.V.; Khomutova, E.V.; Mitchenko, S.A. Catalytic hydrochlorination of acetylene on $\mathrm{PdCl}_{2} / \mathrm{C}$ supported catalysts: Kinetic isotopic effect of $\mathrm{HCl} / \mathrm{DCl}$, stereoselectivity, and mechanism. Kinet. Catal. 2017, 58, 533-540. [CrossRef]

8. $\mathrm{Pu}, \mathrm{Y}$;; Zhang, J.; Yu, L.; Jin, Y.; Li, W. Active ruthenium species in acetylene hydrochlorination. Appl. Catal. A Gen. 2014, 488, 28-36. [CrossRef]

9. Xu, J.; Zhao, J.; Zhang, T.; Di, X.; Gu, S.; Ni, J.; Li, X. Ultra-low Ru-promoted $\mathrm{CuCl}_{2}$ as highly active catalyst for the hydrochlorination of acetylene. RSC Adv. 2015, 5, 38159-38163. [CrossRef]

10. Li, H.; Wang, F.; Cai, W.; Zhang, J.; Zhang, X. Hydrochlorination of acetylene using supported phosphorus-doped Cu-based catalysts. Catal. Sci. Technol. 2015, 5, 5174-5184. [CrossRef]

11. Zhai, Y.Y.; Zhao, J.; Di, X.X.; Di, S.X.; Wang, B.L.; Yue, Y.X.; Sheng, G.F.; Lai, H.X.; Guo, L.L.; Wang, H.; et al. Carbon-supported perovskite-like $\mathrm{CsCuCl}_{3}$ nanoparticles: A highly active and cost-effective heterogeneous catalyst for the hydrochlorination of acetylene to vinyl chloride. Catal. Sci. Technol. 2018, 8, 2901-2908. [CrossRef]

12. Li, X.; Pan, X.; Yu, L.; Ren, P.; Wu, X.; Sun, L.; Jiao, F.; Bao, X. Silicon carbide-derived carbon nanocomposite as a substitute for mercury in the catalytic hydrochlorination of acetylene. Nat. Commun. 2014, 5, 3688. [CrossRef] [PubMed] 
13. Li, X.Y.; Zhang, J.L.; Han, Y.; Zhu, M.Y.; Shang, S.S.; Li, W. MOF-derived various morphologies of N-doped carbon composites for acetylene hydrochlorination. J. Mater. Sci. 2018, 53, 4913-4926. [CrossRef]

14. Chao, S.L.; Zou, F.; Wan, F.F.; Dong, X.B.; Wang, Y.L.; Wang, Y.X.; Guan, Q.X.; Wang, G.C.; Li, W. Nitrogen-doped carbon derived from ZIF-8 as a high-performance metal-free catalyst for acetylene hydrochlorination. Sci. Rep. 2017, 7, 39789. [CrossRef] [PubMed]

15. Li, P.; Li, H.; Pan, X.; Tie, K.; Cui, T.; Ding, M.; Bao, X. Catalytically active boron nitride in acetylene hydrochlorination. ACS Catal. 2017, 7, 8572-8577. [CrossRef]

16. Nkosi, B.; Coville, N.J.; Hutchings, G.J.; Adams, M.D.; Friedl, J.; Wagner, F.E. Hydrochlorination of acetylene using gold catalysts: A study of catalyst deactivation. J. Catal. 1991, 128, 366-377. [CrossRef]

17. Li, X.Y.; Li, P.; Pan, X.L.; Ma, H.; Bao, X.H. Deactivation mechanism and regeneration of carbon nanocomposite catalyst for acetylene hydrochlorination. Appl. Catal. B Environ. 2017, 210, 116-120. [CrossRef]

18. Conte, M.; Carley, A.F.; Hutchings, G.J. Reactivation of a carbon-supported gold catalyst for the hydrochlorination of acetylene. Catal. Lett. 2008, 124, 165-167. [CrossRef]

19. Oliver-Meseguer, J.; Doménech-Carbó, A.; Boronat, M.; Leyva-Pérez, A.; Corma, A. Partial reduction and selective transfer of hydrogen chloride on catalytic gold nanoparticles. Angew. Chem. Int. Ed. 2017, 56, 6435-6439. [CrossRef] [PubMed]

20. Zhao, J.; Gu, S.; Xu, X.; Zhang, T.; Yu, Y.; Di, X.; NI, J.; Pan, Z.; Li, X. Supported ionic-liquid-phase-stabilized $\mathrm{Au}(\mathrm{III})$ catalyst for acetylene hydrochlorination. Catal. Sci. Technol. 2016, 6, 3263-3270. [CrossRef]

21. Zhao, J.; Yu, Y.; Xu, X.L.; Di, S.X.; Wang, B.L.; Xu, H.; Ni, J.; Guo, L.L.; Pan, Z.Y.; Li, X.N. Stabilizing Au(III) in supported-ionic-liquid-phase (SILP) catalyst using $\mathrm{CuCl}_{2}$ via a redox mechanism. Appl. Catal. B Environ. 2017, 206, 175-183. [CrossRef]

22. Zhao, J.; Xu, J.; Xu, J.; Zhang, T.; Di, X.; Ni, J.; Li, X. Enhancement of Au/AC acetylene hydrochlorination catalyst activity and stability via nitrogen-modified activated carbon support. Chem. Eng. J. 2015, 262, 1152-1160. [CrossRef]

23. Wang, L.; Wang, F.; Wang, J. Non-mercury catalytic acetylene hydrochlorination over a $\mathrm{NH}_{4} \mathrm{~F}$-urea-modified $\mathrm{Pd} / \mathrm{HY}$ catalyst for vinyl chloride monomer production. New J. Chem. 2016, 40, 3019-3023. [CrossRef]

24. Wang, L.; Wang, F.; Wang, J. Enhanced stability of hydrochlorination of acetylene using polyaniline-modified Pd/HY catalysts. Catal. Commun. 2016, 74, 55-59. [CrossRef]

25. Cai, J.; Li, L.; Lv, X.; Yang, C.; Zhao, X. Large surface area ordered porous carbons via nanocasting zeolite 10x and high performance for hydrogen storage application. ACS Appl. Mater. Interfaces 2014, 6, 167-175. [CrossRef] [PubMed]

26. Kruk, M.; Jaroniec, M. Gas adsorption characterization of ordered organic-inorganic nanocomposite materials. Chem. Mater. 2001, 13, 3169-3183. [CrossRef]

27. Saxena, P.; Velaga, B.; Peela, N.R. Ionic liquid-encapsulated zeolite catalysts for the conversion of glucose to 5-hydroxymethylfurfural. Chemistryselect 2017, 2, 10379-10386. [CrossRef]

28. Catrinck, M.N.; Ribeiro, E.S.; Monteiro, R.S.; Ribas, R.M.; Barbosa, M.H.P.; Teófilo, R.F. Direct conversion of glucose to 5-hydroxymethylfurfural using a mixture of niobic acid and niobium phosphate as a solid acid catalyst. Fuel 2017, 210, 67-74. [CrossRef]

29. Huddleston, J.G.; Visser, A.E.; Reichert, W.M.; Willauer, H.D.; Broker, G.A.; Rogers, R.D. Characterization and comparison of hydrophilic and hydrophobic room temperature ionic liquids incorporating the imidazolium cation. Green Chem. 2001, 3, 156-164. [CrossRef]

30. Sarvaramini, A.; Gravel, O.; Larachi, F. Torrefaction of ionic-liquid impregnated lignocellulosic biomass and its comparison to dry torrefaction. Fuel 2013, 103, 814-826. [CrossRef]

31. Berijani, K.; Hosseini-Monfared, H. Collaborative effect of Mn-porphyrin and mesoporous SBA-15 in the enantioselective epoxidation of olefins with oxygen. Inorg. Chim. Acta 2018, 471, 113-120. [CrossRef]

32. Zhang, Q.; Su, H.; Luo, J.; Wei, Y. A magnetic nanoparticle supported dual acidic ionic liquid: A "quasi-homogeneous" catalyst for the one-pot synthesis of benzoxanthenes. Green Chem. 2012, 14, 201-208. [CrossRef]

33. Kotov, N.; Šturcová, A.; Zhigunov, A.; Raus, V.; Dybal, J. Structural transitions of 1-butyl-3-methylimidazolium chloride/water mixtures studied by Raman and FTIR spectroscopy and waxs. Cryst. Growth Des. 2016, 16, 1958-1967. [CrossRef] 
34. Wang, M.; Zhang, L.; Gao, L.; Pi, K.; Zhang, J.; Zheng, C. Improvement of the $\mathrm{CO}_{2}$ absorption performance using ionic liquid $\left[\mathrm{NH}_{2} \mathrm{emim}\right]\left[\mathrm{BF}_{4}\right]$ and $[\mathrm{emim}]\left[\mathrm{BF}_{4}\right] /[\mathrm{bmim}]\left[\mathrm{BF}_{4}\right]$ mixtures. Energy Fuels 2013, 27, 461-466. [CrossRef]

35. Mohamedali, M.; Ibrahim, H.; Henni, A. Incorporation of acetate-based ionic liquids into a zeolitic imidazolate framework (ZIF-8) as efficient sorbents for carbon dioxide capture. Chem. Eng. J. 2018, 334, 817-828. [CrossRef]

36. Xu, H.; Han, Z.; Zhang, D.; Zhan, J. Interface behaviors of acetylene and ethylene molecules with 1-butyl-3-methylimidazolium acetate ionic liquid: A combined quantum chemistry calculation and molecular dynamics simulation study. ACS Appl. Mater. Interfaces 2012, 4, 6646-6653. [CrossRef] [PubMed]

37. Wang, L.; Wang, F.; Wang, J. Catalytic properties of Pd/HY catalysts modified with $\mathrm{NH}_{4} \mathrm{~F}$ for acetylene hydrochlorination. Catal. Commun. 2015, 65, 41-45. [CrossRef]

38. Song, Z.; Liu, G.; He, D.; Pang, X.; Tong, Y.; Wu, Y.; Yuan, D.; Liu, Z.; Xu, Y. Acetylene hydrochlorination over 13X zeolite catalysts at high temperature. Green Chem. 2016, 18, 5994-5998. [CrossRef]

39. Li, X.; Wang, Y.; Kang, L.; Zhu, M.; Dai, B. A novel, non-metallic graphitic carbon nitride catalyst for acetylene hydrochlorination. J. Catal. 2014, 311, 288-294. [CrossRef]

40. Li, X.; Pan, X.; Bao, X. Nitrogen doped carbon catalyzing acetylene conversion to vinyl chloride. J. Energy Chem. 2014, 23, 131-135. [CrossRef]

41. Zhang, C.; Kang, L.; Zhu, M.; Dai, B. Nitrogen-doped active carbon as a metal-free catalyst for acetylene hydrochlorination. RSC Adv. 2015, 5, 7461-7468. [CrossRef]

42. Zhang, T.T.; Zhao, J.; Xu, J.T.; Xu, J.H.; Di, X.X.; Li, X.N. Oxygen and nitrogen-doped metal-free carbon catalysts for hydrochlorination of acetylene. Chin. J. Chem. Eng. 2016, 24, 484-490. [CrossRef]

43. Wang, J.; Zhao, F.; Zhang, C.; Kang, L.; Zhu, M. A novel S, N dual doped carbon catalyst for acetylene hydrochlorination. Appl. Catal. A Gen. 2018, 549, 68-75. [CrossRef]

44. Michalak, W.D.; Krier, J.M.; Alayoglu, S.; Shin, J.-Y.; An, K.; Komvopoulos, K.; Liu, Z.; Somorjai, G.A. CO oxidation on PtSn nanoparticle catalysts occurs at the interface of Pt and Sn oxide domains formed under reaction conditions. J. Catal. 2014, 312, 17-25. [CrossRef]

45. Lin, R.; Kaiser, S.K.; Hauert, R.; Pérez-Ramírez, J. Descriptors for high-performance nitrogen-doped carbon catalysts in acetylene hydrochlorination. ACS Catal. 2018, 8, 1114-1121. [CrossRef]

46. Tuma, D.; Maurer, G. Gas solubility in ionic liquids: Mixed gases in pure ionic liquids and single gases in binary liquid mixtures. In Ionic Liquids: Science and Applications; American Chemical Society: Washington, DC, USA, 2012; pp. 217-238.

47. Shinoda, K. The vapor-phase hidrochlorination of acetylene over metal chlorides supported on activated carbon. Chem. Lett. 1975, 4, 219-220. [CrossRef]

48. He, R.-H.; Long, B.-W.; Lu, Y.-Z.; Meng, H.; Li, C.-X. Solubility of hydrogen chloride in three 1-alkyl-3-methylimidazolium chloride ionic liquids in the pressure range (0 to 100) $\mathrm{kPa}$ and temperature range (298.15 to 363.15) k. J. Chem. Eng. Data 2012, 57, 2936-2941. [CrossRef]

49. Xu, J.; Zhao, J.; Xu, J.; Zhang, T.; Li, X.; Di, X.; Ni, J.; Wang, J.; Cen, J. Influence of surface chemistry of activated carbon on the activity of gold/activated carbon catalyst in acetylene hydrochlorination. Ind. Eng. Chem. Res. 2014, 53, 14272-14281. [CrossRef]

50. Mehnert, C.P.; Cook, R.A.; Dispenziere, N.C.; Afeworki, M. Supported ionic liquid catalysis-A new concept for homogeneous hydroformylation catalysis. J. Am. Chem. Soc. 2002, 124, 12932-12933. [CrossRef] [PubMed]

51. Valkenberg, M.H.; deCastro, C.; Hölderich, W.F. Immobilisation of ionic liquids on solid supports. Green Chem. 2001, 4, 88-93. [CrossRef]

52. Fehrmann, R.; Riisager, A.; Haumann, M. Supported Ionic Liquids; Wiley-VCH: Weinheim, Germany, 2014; pp. 128-129.

53. Bovio, S.; Podestà, A.; Lenardi, C.; Milani, P. Evidence of extended solidlike layering in [Bmim][NTf2] ionic liquid thin films at room-temperature. J. Phys. Chem. B 2009, 113, 6600-6603. [CrossRef] [PubMed]

(C) 2018 by the authors. Licensee MDPI, Basel, Switzerland. This article is an open access article distributed under the terms and conditions of the Creative Commons Attribution (CC BY) license (http:/ / creativecommons.org/licenses/by/4.0/). 